\title{
A TRANSGRESSÃO DA MORAL E DOS BONS COSTUMES FEMININOS NA DÉCADA DE 1960: "Leila Diniz: \&\$f7!"1
}

\section{THE TRANSGRESSION OF MORALITY AND GOOD FEMININE CUSTOMS IN THE 1960'S: "Leila Diniz: \&\$£7!"}

Barbara Fonseca ${ }^{2}$

Resumo: O presente artigo busca discutir o tema da transgressão da moral e dos bons costumes femininos na década de 1960 no Brasil a partir da famosa entrevista de Leila Diniz concedida ao jornal $O$ Pasquim, edição no 22, de 20 a 26 de novembro de 1969. Ao analisar as falas da atriz destacamos os comportamentos divergentes aos que seriam considerados normativos para as mulheres na época. Leila Diniz se posicionava a favor do amor livre, da liberdade sexual, falava palavrões e, dessa maneira, expunha o que muitas vezes era feito em segredo pelas mulheres, que não podiam expressar desta maneira em público, muito menos na imprensa. Ao ser inconformista e transgressora, Leila Diniz abriu caminho para outras mulheres encontrarem suas liberdades.

Palavras-chave: Leila Diniz; O Pasquim; Ditadura Militar; Censura; História das Mulheres.

Abstract: This article seeks to discuss the feminine transgression of morality and good manners in the 1960s in Brazil from the famous interview of Leila Diniz granted to the newspaper $O$ Pasquim, edition $\mathrm{n}^{\mathrm{o}} 22$, november 20-26, 1969. Therefore, when analyzing the speeches of the actress, we observed behaviors divergent from those that would be considered normative for the women in the period. Leila Diniz was in favor

\footnotetext{
${ }^{1}$ Manchete de capa do jornal O Pasquim, no 22.

2 Graduada no curso de História (Licenciatura e Bacharelado) da Universidade Federal do Paraná e mestranda na mesma instituição. Email para contato: fonseca.bah@gmail.com. Endereço para o Currículo Lattes: http://lattes.cnpq.br/9195216424270749.
} 
of the free love, the sexual freedom, spoke dirty words, and, thus, exposed what was often done in secret, but was not said to society. As a woman who was part of her time, for being who it was, Leila Diniz made way for other women to find their freedoms.

Keywords: Leila Diniz; O Pasquim; Brazilian Military Dictatorship; Censorship; Women's History.

\section{Censura, Leila Diniz e a entrevista ao Pasquim}

O presente artigo é resultado de um trabalho de análise de fontes históricas para a disciplina de História do Brasil IV do curso de História Licenciatura e Bacharelado da Universidade Federal do Paraná. Nele, buscamos discutir a transgressão da moral e dos bons costumes femininos da década de 1960 no Brasil a partir da entrevista concedida por Leila Diniz ao Pasquim, na edição $\mathrm{n}^{\mathrm{o}}$ 22, de 20 a 26 de novembro de 1969. Selecionamos esta entrevista como fonte uma vez que nela Leila Diniz se apresenta de maneira diametralmente oposta ao que era considerado um exemplo de bom comportamento das mulheres honestas e "direitas" para a época: conta abertamente sobre sua vida sexual, manifesta-se a favor do amor livre e fala palavrões. Ademais, essa entrevista pode ser considerada um ponto de inflexão no cerceamento da liberdade de expressão da imprensa brasileira, visto que, dois meses após a publicação da entrevista, o regime militar brasileiro baixou o Decreto 1.077. Esse, popularmente conhecido como "Decreto Leila Diniz", passou a permitir a censura prévia à imprensa.

O Pasquim era um jornal alternativo, sem patrocínio de empresários (QUEIROZ, 2004: 232). Foi criado em fins de 1968 pelo cartunista Jaguar 
e pelos jornalistas Tarso de Castro e Sérgio Cabral, que buscavam uma alternativa de jornal de humor para o tabloide humorístico $A$ Carapuça, que não resistiu à morte de seu editor, Sérgio Porto (AUGUSTO, não p.). Segundo afirma Sérgio Augusto (não p.), o nome custou a sair. "Que tal Pasquim?”, sugeriu Jaguar, que àquela altura já atraíra o também cartunista Claudius e o publicitário Carlos Prósperi para cuidarem do projeto gráfico. "Vão nos xingar mesmo de pasquim", justificou Jaguar a preventiva “Carapuça”. Em 1969, seu primeiro ano de publicação, O Pasquim contava com a impressão de cerca de 20 mil exemplares por edição, ao passo que no fim do mesmo ano multiplicaria quase dez vezes o número de seus exemplares, sendo o jornal alternativo mais vendido do país.

Sendo um espaço livre de ideias, o jornal era aberto ao pensamento crítico e publicava os mais diversos assuntos, como temas referentes à contracultura e entrevistas com personalidades controversas. $\mathrm{O}$ humor e a oralidade dos textos eram características marcantes, conforme apontaremos na entrevista concedida por Leila Diniz. Ademais, o jornal também contava com diversos colaboradores, como Ziraldo, por exemplo, que publicava seus cartuns nas páginas do Pasquim.

Contudo, apesar do grande sucesso no fim da década de 1960, nos anos 1970 muitos de seus autores foram presos pelo regime militar após o jornal ter publicado uma sátira do quadro Independência ou Morte, de autoria de Pedro Américo (MARQUES, 2020, não p.). Conforme afirmou Pereira (2007: 14), após a prisão, os militares esperavam que o jornal saísse de circulação e/ou seus leitores perdessem o interesse, entretanto, não foi o 
que aconteceu. Millôr Fernandes com colaborações de outros intelectuais como Rubem Fonseca, Odete Lara, Chico Buarque, Glauber Rocha entre outros, continuaram a editar e publicar O Pasquim. Assim, as prisões continuaram nos anos seguintes. O jornal também foi alvo de dois atentados à bomba, bem como as bancas que vendiam jornais alternativos nos anos 1980. Depois desses episódios, muitas dessas bancas decidiram não mais revender $O$ Pasquim, o qual se enfraqueceu cada vez mais até deixar de existir em 1991.

A entrevista de Leila Diniz, conforme já afirmado, é marcante na história da imprensa brasileira, na medida em que ultrapassa diversas barreiras da moral conservadora do período, afrontando o regime militar, que, a partir desse episódio, intensificou a censura no país. Segundo Adriana Setemy (2018: 175), "a censura consistiu em um instrumento político legítimo perante setores da sociedade civil, um endosso do Estado àquilo que era considerado pertinente aos valores da família cristã”.

$\mathrm{Na}$ prática, de acordo com Renato Ortiz (1988: 114), “a censura possuía duas faces: uma repressiva, outra disciplinadora.” O que significa que a repressiva, obviamente, dizia não; e a disciplinadora agia como "repressão seletiva". Ou seja, obrigava o desaparecimento de partes das criações culturais, mas não proibia o espetáculo em si. Setemy complementa tal entendimento ao apresentar que a censura era legalizada desde 1945 pelo órgão chamado de Serviço de Censura de Diversões Públicas (SCDP), o qual proibia "peças de teatro, cinema, programas de rádio e televisão, espetáculos musicais e circenses, em defesa da 
moralidade e dos bons costumes do povo brasileiro". Em contrapartida, a censura da imprensa seria acobertada, "sem ser regulamentada por um órgão específico" (SETEMY, 2018: 181).

A censura existia desde os primeiros anos após o golpe militar, visto o SCDP. Contudo, com a Constituição de 1967 observamos a instituição da restrição à liberdade de expressão, uma vez que no artigo 153 fica claro: “A publicação de livros, jornais e periódicos independe de licença de autoridade. Não será, porém, tolerada a propaganda de guerra, de subversão da ordem ou de preconceitos de raça ou de classe" (CONSTITUIÇÃO BRASIL, 1967). Mesmo assim, a censura prévia só foi instituída a partir de 1970 com o Decreto n¹.077 assinado pelo presidente Médici. Esse, por sua vez, além de estabelecer o exame prévio das publicações, reforçava o que já previa o texto constitucional da Ditadura (QUINALHA, 2017: 58).

Sabemos que nada na História é linear e uníssono, e assim também não seria a censura. Mesmo com o suporte legislativo, a censura segue o caminho traçado por Ortiz, sendo, em diversos momentos, "apenas" disciplinadora. Nesse sentido, ainda, subscrevemos a afirmação de Carlos Fico (2004: 37), de que "a censura à imprensa era praticada de maneira acobertada, através de bilhetinhos ou telefonemas que as redações recebiam". Não podemos ignorar a subjetividade na ação censora de acordo com quem, quando e onde ela se aplicava.

Não é possível entender a publicação da entrevista de Leila Diniz sem saber como se aclimatavam as proibições em 1969, uma vez que Leila em inúmeros momentos de sua declaração andou na contramão dos bons 
costumes desejados pela sociedade conservadora do período. Pode ser difícil compreender que em meio aos "Anos de Chumbo" os militares não proibiram a entrevista, contudo, conforme já afirmado, em 1969 a censura ainda não se fazia previamente disciplinadora à imprensa. Assim, $O$ Pasquim encontrou uma solução para contornar a disciplinarização da censura a fim de evitar a apreensão de suas impressões: trocou todos os palavrões por asteriscos.

Com a publicação da entrevista, observamos suas consequências. Além do já mencionado Decreto 1.077 e da intensificação da perseguição aos autores do Pasquim, Leila também sofreu perseguição, sendo demitida da TV Globo ${ }^{3}$ e perseguida pelo regime, quando teve que se esconder no sítio de seu amigo Flávio Cavalcanti que posteriormente a colocaria como jurada de seu programa de calouros na TV Tupi. É importante perceber que mesmo Leila Diniz não tendo participado de movimentos ou partidos políticos, incomodou o regime militar com suas declarações dadas a $O$ Pasquim, uma vez que sua afronta à normatividade sexual feminina do período era considerada perigosa assim como ser atuante dos movimentos de esquerda.

Não deve-se simplificar a participação política de Leila, pois apesar dessa aparente "ausência" nos movimentos sociais, veiculada na própria

${ }^{3}$ Conforme afirmou Ricky Goodwin em suas memórias publicadas na Biblioteca Nacional Digital (não p.), "Leila foi demitida sumariamente da TV Globo, onde era uma popular mocinha das novelas. Foram duros: 'Puta não trabalha aqui'. Ou: '(*) não trabalha aqui'”. 
entrevista concedida a $O$ Pasquim, Leila se posiciona contra ao ser questionada sobre a censura à arte:

De jeito nenhum. Foi o que eu perguntei aos censores: que tipo de preparo tem uma pessoa que vai julgar e censurar uma obra de arte? Eu não teria coragem de ser censor. Se eu fosse julgar uma obra de arte, eu teria de ser uma pessoa inteligentérrima, cultérrima, muito humana e muito por dentro das coisas. Censura é ridículo, não tem sentido nenhum. Do jeito que é feita, inclusive, não tem nenhuma noção de justiça, cultura, nem nada (DINIZ, 1969).

Nascida em 1945 em Niterói, no Rio de Janeiro, desde muito nova Leila Diniz trabalhou como professora, até que em 1965 atuou em sua primeira novela. Daí em diante, tornou-se uma importante atriz brasileira, realizando, em 1966, um de seus principais filmes, Todas as mulheres do mundo, dirigido por seu ex-companheiro Domingos de Oliveira. Leila em sua entrevista a $O$ Pasquim, nega que sua entrada no cinema tenha ocorrido devido à sua relação amorosa com Domingos de Oliveira, como muitos poderiam pensar.

$\mathrm{Eu}$ fiquei com o Domingos, sendo professora, e ainda estudando porque estava fazendo o Clássico à noite. Eu ensinava de dia. Fiquei com o Domingos uns três anos, durante um ano e meio eu ainda era professora, depois já era atriz. Como a gente era muito duro, o Domingos escrevia para a Manchete, jornal, (*) a quatro, escrevia peças e aquelas coisas, a gente não ganhava dinheiro nenhum e eu ganhava pouco também como professora, então eu fui fazer anúncio. 
[...]. Eu entrei na televisão, inclusive, por isso. Não foi através de Domingos (DINIZ, 1969).

Mesmo sendo famosa na televisão e no cinema brasileiro, Leila é constantemente lembrada apenas por seus comportamentos desviantes. Muito antes de a segunda onda do feminismo ganhar força no Brasil, Leila Diniz já questionava a repressão sexual e também o lugar social das mulheres, a virgindade compulsória, o casamento, o conhecimento do próprio corpo e as "boas maneiras" que impediriam a liberdade do corpo e de expressão, como falar "palavrões", sair com quem e quando quisesse.

Estas ideias e seus comportamentos, apesar de não parecerem "incríveis" aos nossos olhos do século XXI, foram sim transgressores e tiveram forte impacto na aceitação e no respeito a Leila Diniz por parte da sociedade. A atriz, que simplesmente por ser atriz já carregava o estigma de uma mulher "não direita", por se fazer livre, era considerada desviante, promíscua pervertida, "galinha” e ninfomaníaca (GOLDENBERG, 1996: 180). Esse estigma foi carregado não só por ela, mas também pelas pessoas que estavam à sua volta. É marcante a fala de sua irmã Regina, em entrevista dada para Mirian Goldenberg para compreender um pouco mais do pensamento da época a respeito de Leila, bem como ilustra como a atriz lidava quase sempre de maneira divertida com os insultos:

Quando entrei pra faculdade, tive mil paqueras em cima de mim por ser a irmã de Leila Diniz. Os caras da faculdade achavam que por ser irmã dela eu tinha obrigação de transar. Minha irmã fez uma revolução, abriu a cabeça de muita gente, mas muita gente encarava isso como galinhagem. Então me 
fechei muito pra lance de paquera. Logo eu, que sempre gostei, mesmo namorando, de fazer um charmezinho. Mas na faculdade eu me defendia. A Leila, sempre palhaça, quando estava grávida, dizia 'essa aqui é a irmã da puta, essa aqui na barriga, vai ser a verdadeira filha da puta'. Eu era a irmã da puta (GOLDENBERG, 1996: 182).

Conforme afirma Natanael Silva (2016: 78), Leila Diniz “ficou marcada como uma ameaça ao modelo heteronormativo de família por falar publicamente dos seus amores e afetos.” E seria um engano acreditar que a reação negativa à Leila se fazia apenas pelos militares e da parte considerada "conservadora" da sociedade. Sim, segundo Silva (2016: 78), "para os militares ela era um péssimo exemplo às jovens solteiras, por fazer apologia ao sexo fora do casamento." Contudo, para grupos que em muitos momentos consideraríamos progressistas e também transgressores, a atriz também era um incômodo.

Conforme discute o autor, "para grupos de esquerda, ela era vista como alienada" (SILVA, 2016: 78). Afinal, os movimentos de esquerda, em sua maioria, consideravam as pautas femininas e feministas como de menor importância, uma vez que os esforços deveriam ser concentrados nas ações políticas contra a Ditadura Militar. Parafraseando o bordão feminista, o pessoal ainda não era político e as mulheres que simpatizavam com o feminismo pouco encontravam espaço para expressar suas ideias. Além disso, para fugir do estigma de um movimento burguês, parte da esquerda considerava que Leila, por defender a liberdade sexual, representava uma postura vulgar e não militante (SILVA, 2016: 78). 
A entrevista concedida a $O$ Pasquim é precedida de uma breve explicação acerca de Leila e de sua liberdade, carregada de humor, assim como de costume no periódico. A partir deste pequeno excerto, já se nota o posicionamento crítico e satírico tanto de Leila Diniz quanto do jornal, uma vez que são enfatizadas a alegria e a liberdade em ser de fato quem se é. Segue o aviso, que mais se assemelha a uma anedota, quanto à intervenção dos jornalistas nos palavrões ${ }^{4}$ :

Leila Diniz é chapinha d'O PASQUIM e sua entrevista é mais do que na base do muito à vontade. Durante duas horas ela bebeu e conversou com a equipe de entrevistadores numa linguagem livre e, portanto, saudável. Seu depoimento é o de uma moça de 23 anos que sabe o que quer e que conquistou a independência na hora em que decidiu fazer isto. Leila é a imagem da alegria e da liberdade, coisa que só é possível quando o falso moralismo é posto de lado.

(Cada palavrão dito pela rósea boquinha da bela Leila foi substituído por uma estrelinha. É por isso que a entrevista dela até parece a via-láctea) (O PASQUIM, 1969).

Notamos que as perguntas iniciais para Leila Diniz são sobre sua profissão de atriz, seus papéis, trabalhos, mas que acabam por serem enviesadas pela vida pessoal de Leila, com perguntas sobre os namorados,

\footnotetext{
${ }^{4}$ Ao longo da entrevista, Leila Diniz não deixa de ser questionada pela "patota" sobre o uso de palavrões, os quais para ela, seriam usuais à sua maneira de se expressar. Apesar de ferirem os bons costumes, não só da época mesmo que sejam naturalizados no dia a dia, como também hoje, Leila afirma que não se sentia incomodada ao dizê-los, ao passo que com o passar dos anos foi ficando mais desinibida e segura, e assim, mais tranquila ao se expressar como bem entendia.
} 
os gostos e sua liberdade sexual. A "patota", nome que se convencionou chamar os autores de $O$ Pasquim, em certo momento questiona sobre um novo trabalho da atriz: "Vai ter strip-tease?" E Leila, por sua vez, responde: "Não sei. Se tiver eu também faço, pô." Na pergunta seguinte, fugindo da ênfase no trabalho, é perguntado: "Você gosta de mulher?" E Leila, perspicaz, expõe o amor e conhecimento pelo seu próprio corpo, ultrapassando costumeiramente o não-dito pelas mulheres do período: "Gostei de mim, quando fui tomar banho pelada de noite e tem aquela água que fica brilhando com a lua. Você quer morrer: fica com aquelas gotinhas prateadas no corpo, divina e maravilhosa".

Mesmo em 1969, O Pasquim já levantava uma questão muito discutida nos dias de hoje acerca do assédio contra as atrizes: "Quer dizer que o pessoal da televisão tem exigências não-profissionais? Ficam querendo faturar as moças, é isso?” Leila, por sua vez, não nega que exista o assédio, demonstrando que sua forte posição e personalidade dentro dos bastidores evitam o assédio sexual - o que, segundo ela, poderia não ser uma realidade para atrizes mais novas -, mas ainda a colocam no jogo da condescendência para conseguir um papel.

Não está tanto mais assim, não. Já esteve muito. A mim, nunca quiseram, porque eu mando logo tomar no (*). Quando eu quero, eu vou com o cara. Comigo não tem esse negócio de ninguém querer, não. Quer dizer: pra mim, não tem. Talvez tenha pras mocinhas que estão começando. Eu não sei, não. Tem é muita zona em volta que não é negócio do (*), que

${ }^{5}$ Entre os entrevistadores estavam: Tarso de Castro, Jaguar, Sérgio Cabral, Paulo Garcez, Luiz Carlos Maciel e Tato Taborda. 
talvez fosse até mais fácil, você chegava lá e pronto, afinal, (*), não é tão ruim mesmo. O que tem é toda uma paparicação que é desagradável, entende? Você tem de jantar com fulano, conviver com sicrano, bater papo, tomar uisquinho, nhem, nhem e tal. Isso existe muito mais do que o dar. Está até fora de moda esse negócio de (*) (DINIZ, 1969).

A partir dessa passagem percebe-se como Leila era uma mulher decidida quanto a sua sexualidade, não tendo "papas na língua" para dizer o que a incomodava. Conforme já discutido, muitas vezes Leila Diniz foi considerada promíscua, entretanto, apesar de a mesma em muitos momentos "fazer graça” das acusações, na entrevista demonstra que não é o que a imprensa costumava divulgar. Quando perguntada sobre as cantadas realizadas pelos fãs, responde:

[os fãs] fazem um certo charme. Dizem que vêem meus filmes, lêem minhas entrevistas. E como todas as minhas entrevistas dizem: "Leila, a mulher livre", "Leila, a mulher que faz o amor", "Leila que é independente" etc, todo mundo fica achando que sou aquela $(*)$ da zona, não é? E realmente os moçoilos ficam um pouco interessados. Mas aí eu dou aquela de: não é nada disso, rapaz, que é isso, estamos aí, mas não é bem assim. Eu tiro de letra [...] (DINIZ, 1969).

Seguindo nesse mesmo caminho, foi questionada: "Um aviso aos navegantes: quem escolhe é você, não é?" E Leila responde: "Sei lá. Acho que a gente escolhe. Acho que sou eu que (*), sim." A partir dessa declaração Mirian Goldenberg afirma que "Leila inverte os papéis culturais definidos de "ativo" e "passivo" durante a interação sexual. Mais uma vez 
reafirma a condição de sujeito de seu corpo e de sua sexualidade, aproximando-se do polo masculino/ativo" (GOLDENBERG, 1996: 201). Apesar de Goldenberg não citar Peter Fry, entendemos que tal modelo analítico de "ativo e passivo" faz referência ao livro Para Inglês Ver (FRY, 1982), o qual contribuiu para o início dos estudos de gênero no país, embora este conceito não fosse usado à época.

É importante perceber que Leila Diniz fazia o que amava e acreditava que as pessoas deveriam fazer o que as deixassem bem. Para ela, a liberdade era isso, independente do que é "normal" dentro da sociedade. conforme afirmou:

a análise me fez muito bem, da mesma maneira que o ginecologista me fez bem quando eu precisei. Voltarei sempre que precisar. Acho que cada um deve fazer o que lhe faz bem. Se você fumar maconha e achar que isso lhe cura, acho ótimo. O importante é amar as pessoas e sentir uma certa felicidade, apesar da zona ao teu redor (DINIZ, 1969).

Quando a patota questiona sobre a idade em que perdeu a virgindade, virtude essencial para uma mulher "direita" no período, Leila com certeza escandalizou com sua resposta de que teria sido com 15 para 16 anos e que não era nem muito nova e nem muito velha, mas teria sido na hora ideal. Além disso, contra toda a dignidade e moralidade do casamento, afirma que não poderia dizer quem foi o primeiro homem, pois "ele é casado e pode dar problema. Não vou me meter na vida dos outros, não é?" Sendo 
considerada ainda mais "mundana", afirmou que ele não "ficou sendo um homem importante na sua vida", fora apenas o primeiro entre outros.

É importante ressaltar que mesmo após 50 anos da realização da entrevista, muito do que disse Leila Diniz ainda é questionado nos dias de hoje. Ao afirmar a sentença de Jaguar, de que "amar e ir pra cama não é a mesma coisa", Leila completa

Eu acho bacana ir pra cama. Eu gosto muito, desde que dê aquela coisa de olho e pele que já falei. Agora, sobre o amor, eu não acredito nesse amor possessivo e chato. Você pode amar muito uma pessoa e ir pra cama com outra. Isso já aconteceu comigo.

Mas, para Leila, isso não significava que ela era infiel, como a própria afirma: “Quando eu estou com uma pessoa, eu fico muito ocupada com ela. Eu sou muito de me ocupar. Agora, a ideia do amor é geralmente tão possessiva que me irrita muito. Detesto aquele negócio de saber hora, o que fez, etc."

Sem dúvida Leila Diniz foi uma transgressora da moral e dos bons costumes do período, contudo, ela não se considerava alguém à frente de seu tempo:

Eu não sou uma pessoa vinda de Marte. Eu nasci em 1945 e fui criada por uma família burguesa, razoavelmente bacana, mas eu tenho todos esses problemas dentro de mim. Evidentemente, eu também procuro um pai, um pouco. Tanto eu quero isso, que eu sou sozinha. Mas, pra mim, é mais importante as coisas em que eu acredito. Por isso, eu abro mão dessa proteção pra continuar no meu caminho. Mas, às vezes, 
dentro da sociedade que a gente vive, é bacaninha você ter um homem do teu lado, nem um homem - viu? - um companheiro, um treco bacana. Alguém que diga: está pegando fogo? Então vamos apagar juntos. O maridinho que eu quis dizer é isso (DINIZ, 1969).

O papel que Leila exerce é o de questionar o mesmo, de se colocar em primeiro lugar, de não aceitar a imposição social, mas também de não se opor aos homens, nem aos relacionamentos sexo-afetivos. É essencial perceber que o que Leila fala poderia não ser nenhuma novidade no período para muitas pessoas, afinal nos segredos de cada um, moram ações e reações imagináveis para outros. Contudo, conforme afirma Goldenberg, Leila Diniz contribuiu para a revolução na maneira de agir das mulheres, uma vez que "[trouxe] à luz do dia comportamentos femininos já existentes, mas que eram vividos como estigmas, proibidos, ocultos, recalcados" (GOLDENBERG, 1996: 185).

Para além dessa entrevista, sabemos de diversas outras atitudes tomadas por Leila Diniz que acabaram por causar "alvoroço" na sociedade, como sua fala "transo de manhã, de tarde e de noite" ou a sua aparição de biquíni na praia enquanto estava grávida, algo inimaginável para o período, uma vez que o papel de mãe era o de "santa" e havia um tabu forte em relação ao corpo grávido. Quanto a esse chamativo posicionamento na mídia, a própria Leila explicou que apenas estava sendo ela mesma:

Vieram as mil entrevistas e como nunca tive nada com esse negócio de ser atriz, de construir uma imagem para o público, eu falava exatamente o que eu estava pensando. E acho que foi 
aí que aconteci. O pessoal percebeu que eu tinha mil facetas para serem badaladas. A diferença entre mim e as outras pessoas do meio é que, enquanto elas estavam apenas falando, eu gritava tudo o que tinha para gritar. Passei a ser uma moça sexy e todos se perguntavam: mas moça sexy pensa? As pessoas passaram a me dar muita atenção. A imprensa capitalizou e tudo quanto eu falava virava imediatamente uma zorra. Não sei se foi loucura ou coragem minha, mas sempre me expus muito. De certa forma, acho que é isso que ainda sustenta essa coisa engraçada chamada mito (DINIZ, 2011: 199).

Segundo Goldenberg (2011: 209), muitas mulheres faziam ou diziam as mesmas coisas que Leila, contudo Leila "dizia e fazia", "acumulando assim reconhecimento dos que desejavam contestar o modelo tradicional de ser mulher." Nesse sentido, Leila Diniz não era uma mulher à frente de seu tempo, mas, com certeza foi uma mulher ímpar, pois teve coragem de fazer e falar o que queria e sobre o que fazia, em um período no qual as mulheres deveriam se adequar aos conselhos dos manuais de educação que as orientavam a ser submissas, recatadas e do lar. Este modelo restrito e limitado de feminilidade levou a represálias não só para Leila, mas também para a liberdade de expressão no regime militar.

Apesar de seus atritos com a militância de esquerda e de não se considerar feminista, hoje Leila Diniz é um ícone para o feminismo da quarta onda. Afinal, o que é o feminismo se não a luta pela liberdade de poder ser quem se é de verdade?

\section{Referências}


AUGUSTO, Sérgio. O marginal que deu certo. Biblioteca Nacional Digital Brasil. Dossiês. O Pasquim. História. Disponível em: $<$ https://bndigital.bn.gov.br/dossies/o-pasquim/historia-o-pasquim/1969-19 79-por-sergio-augusto/>. Acesso em: 19 nov. 2020.

CRUZ, Sebastião C. Velasco; MARTINS, Carlos Estevam. De Castello a Figueiredo: uma incursão na pré-história da "abertura". In: ALMEIDA, Maria Hermínia Tavares de; SORJ, Bernardo (orgs.). Sociedade e Política no Brasil pós-64. Rio de Janeiro: Centro Edelstein de Pesquisas Sociais, 2008. pp. 8-90.

DINIZ, Leila. In: GOLDENBERG, Mirian. Toda mulher é meio Leila Diniz. $2^{\mathrm{a}}$ ed. Rio de Janeiro: BestBolso, 2011.

FICO, Carlos. Versões e controvérsias sobre 1964 e a ditadura militar. Revista Brasileira de História, São Paulo, v. 24, n. 47, p. 29-60, 2004.

FRY, Peter. Para Inglês ver: identidade e política na cultura brasileira. Rio de Janeiro, Zahar, 1982.

GOLDENBERG, Mirian. Toda mulher é meio Leila Diniz. $2^{\mathrm{a}}$ ed. Rio de Janeiro: Editora Record, 1996.

GOLDENBERG, Mirian. Toda mulher é meio Leila Diniz. $2^{\mathrm{a}}$ ed. Rio de Janeiro: BestBolso, 2011.

GOODWIN, Ricky. Biblioteca Nacional Digital Brasil. Dossiês. O Pasquim. Memórias. Disponível em: $<$ https://bndigital.bn.gov.br/dossies/o-pasquim/memorias/ricky-goodwin/>. Acesso em: 19 nov. 2020.

MARQUES, Rogério. Pasquim: 50 anos da prisão de uma redação de craques. Jornal GGN. 18 nov. 2020. Disponível em: $<$ https://jornalggn.com.br/memoria/pasquim-50-anos-da-prisao-de-uma-red acao-de-craques-por-rogerio-marques/>. Acesso em: 19 nov. 2020. 
NAPOLITANO, Marcos. 1964: História do Regime Militar Brasileiro. São Paulo: Contexto, 2014. pp. 135 - 157.

ORTIZ, Renato. A moderna tradição brasileira. São Paulo: Brasiliense, 1988. pp.113-148.

PEREIRA, Vinícius Brasileiro Ramalho. O Pasquim e o humor hoje: A influência de um "nanino" na imprensa e a situação atual do humor nos meios de comunicação. 32 f. Trabalho de Graduação (Bacharelado em Comunicação Social) - UniCEUB - Centro Universitário de Brasília. Brasília, 2007.

QUEIROZ, Andréa Cristina de Barros. O PASQUIM: um jornal que só diz a verdade quando está sem imaginação (1969-1991). Revista História \& Perspectivas, Uberlândia, v. 1, n. 31, 2004. Disponível em: $<$ http://www.seer.ufu.br/index.php/historiaperspectivas/article/view/19137> . Acesso em: 20 abr. 2019.

QUINALHA, Renan Honorio. Capítulo 1: A censura em nome da moral e dos bons costumes. Contra a moral e os bons costumes: A política sexual da ditadura brasileira (1964-1988). Tese de Doutorado. Universidade de São Paulo. 2017. Disponível em: $<$ http://www.teses.usp.br/teses/disponiveis/101/101131/tde-20062017-1825 52/en.php>. Acesso em 16 abr. 2019.

SETEMY, Adrianna Cristina Lopes. Vigilantes da moral e dos bons costumes: condições sociais e culturais para a estruturação política da censura durante a ditadura militar. Topoi, Rio de Janeiro, v. 19, n. 37, 2018. pp. 171-197. Disponível em: $<$ http://www.scielo.br/scielo.php?pid=S2237-101X2018000100171\&script =sci_abstract\&tlng=es $>$. Acesso em: 16 abr. 2019.

SILVA, Natanael de Freitas. Ditadura civil-militar no Brasil e a ordem de gênero: masculinidades e feminilidades vigiadas. Mosaico, Rio de Janeiro, v. 7 , n. 11, 2016. pp. 64-83. Disponível em: 
Cadernos de Clio, Curitiba, v. 10, nº. 2, 2019

$<$ http://bibliotecadigital.fgv.br/ojs/index.php/mosaico/article/view/64778>. Acesso em: 16. abr. 2019.

\section{Fontes}

O Pasquim. Rio de Janeiro, $\mathrm{n}^{\circ} 22,20$ a 26 de nov. 1969.

DINIZ, Leila. Entrevista de Leila Diniz a O Pasquim. O Pasquim. Rio de Janeiro, $n^{\circ} 22,20$ a 26 de nov. 1969.

Recebido em: 09/12/2019

Aceito em: 02/12/2020 